\title{
An aptamer targets HBV core protein and suppresses HBV replication in HepG2.2.15 cells
}

\author{
ZUOWEI ZHANG ${ }^{1,2}$, JUN ZHANG ${ }^{1}$, XIAOYU PEI ${ }^{1}$, QI ZHANG ${ }^{1,2}$, BIN LU $^{1}$, XIAOJIAO ZHANG ${ }^{1,2}$ and JIE LIU ${ }^{1,2}$ \\ ${ }^{1}$ Department of Digestive Diseases, Huashan Hospital, and ${ }^{2}$ Institutes of Biomedical Sciences and \\ Department of Immunology of Shanghai Medical School, Fudan University, Shanghai, P.R. China
}

Received February 22, 2014; Accepted August 11, 2014

DOI: $10.3892 /$ ijmm.2014.1908

\begin{abstract}
Hepatitis B virus (HBV)-related hepatitis is a major health concern worldwide. As current anti-HBV therapies are limited, it is essential to develop new strategies. Aptamer, a newly developed adaptive molecule (single-strand DNA or RNA also known as nucleotide antibody), is a new strategy for clinical diagnosis and therapy due to its high affinity and specificity. In the present study, by systematic evolution of ligand by exponential enrichment (SELEX), aptamers were screened against the core protein of HBV $(\mathrm{HBc})$ from a random ssDNA library. Quantitative PCR (qPCR) results showed that the binding proportions of the SELEX-enriched aptamer pools were increased with the SELEX rounds, until round seven. Thus, the pool of round seven was cloned. Following the sequence analysis of a total of 90 clones by MACAW software, five aptamer candidates were selected and their affinity to HBc was tested by dot blot. Apt.No.28, which had sequence replicates in the clones, was shown to have a high affinity. Furthermore, by agarose gel electrophoresiscapillary transfer-blotting and qPCR, Apt.No.28 was shown to inhibit the assembly of the nucleocapsid, reducing extracellular HBV DNA whose synthesis relied on the formation of the nucleocapsid, indicating its role in suppressing HBV replication. The results provided a new ideal targeting molecule and may facilitate the strategy for targeted therapy as well as drug development of HBV-related diseases.
\end{abstract}

\section{Introduction}

Hepatitis B, which is caused by hepatitis B virus (HBV), is a key infectious disease and a major health concern worldwide. In China alone, there are 130 million HBV carriers and 30 million liver disease patients, of whom 300 thousand

Correspondence to: Dr Jie Liu, Department of Digestive Diseases, Huashan Hospital, Fudan University, 12 Middle Wulumuqi Road, Shanghai 200040, P.R. China

E-mail: jieliu@fudan.edu.cn

Key words: aptamer, hepatitis B virus, the core protein of hepatitis B virus succumb to the disease annually (1). Vaccines and appropriate immunization strategies have decreased the infectious rate of HBV, especially in young people. However, with regard to the infected and chronic hepatitis B patients, because of drug resistance and side-effects, the curative effects of current antiHBV therapies (nucleoside analogues and interferons) are still not ideal (2).

The HBV genome contains the coding regions $\mathrm{P}, \mathrm{S}, \mathrm{C}$ and $\mathrm{X}$. The proteins (antigens) encoded by these regions are key markers for the detection of HBV infection. It is believed that targeting the proteins involved in the life cycle of $\mathrm{HBV}$ is an ideal strategy or orientation for the treatment of HBV and related liver diseases (3). The core protein ( $\mathrm{HBc}$ ) encoded by the $\mathrm{C}$ region is crucial in the assembly of the nucleocapsid of $\mathrm{HBV}$, which is composed of 180 or 240 copies of core proteins, and affects its envelopment (4). Thus, drugs targeting the core protein may effectively inhibit the maturation of HBV, which is the end-point of its complete life cycle (5). Therefore, focus on the intervention of $\mathrm{HBc}$ is essential in the identification of anti-HBV therapy.

As a new class of adaptive molecules, aptamer is a single-strand DNA or RNA screened through the SELEX (systematic evolution of ligands by exponential enrichment) technique that can target a wide range of metallic ions, polypeptides, proteins or even cells $(6,7)$. Considered as a nucleic acid antibody, the sensitivity and specificity of aptamer is comparable or even superior to conventional antibodies. The classical example of the application of aptamer is pegaptanib $(8,9)$, which is the aptamer targeting vascular endothelial growth factor (VEGF) and used to treat age-related macular degeneration. As the first approved aptamer drug, it has become a milestone in studies on aptamers.

HIV (10) and HCV (11-13) have been the focus of many antiviral aptamer studies. The most significant came from an in vivo therapeutic attempt of an anti-HIV gp120 aptamer conjugated with siRNA $(14,15)$. Concerning HBV, aptamers targeting $S$ protein (16) and the polymerase (17) were also reported. These findings may definitely improve the use of drugs in clinic as well as drug development.

In the present study, we successfully screened a DNA aptamer targeting $\mathrm{HBc}$. To the best of our knowledge, the findings of this study, reported for the first time, hold great prospect in inhibiting the maturation and replication of $\mathrm{HBV}$. Therefore, the aptamer is a potentially useful tool that can be 
used in the diagnosis of HBV-related diseases and the development of a drug-targeted delivery system (18).

\section{Materials and methods}

Expression and purification of core protein dimers. The core protein sequence was amplified from the plasmid pBS_ HBV3.6II, which was obtained from the Shanghai Medical School, Fudan University and contained complete sequences of HBV genome using the primers: 5'-GCCCATATGGACA TTGACCCGTA-3' and 5'-GCCCTCGAGTCAAACAACAG TAGTTT-3'. The sequence was then cloned into the $\mathrm{NdeI} / \mathrm{XhoI}$ site of pET28a. The recombinant plasmid pET28a-HBc was transformed into Escherichia coli BL21(DE3) to express the core protein at $32^{\circ} \mathrm{C}$. The plain pET28a was also transformed as a negative control.

Following induction with $1.0 \mathrm{mM}$ IPTG for $4 \mathrm{~h}$, the transformed BL21(DE3) cells were washed and re-suspended in the binding buffer (50 mM NaH${ }_{2} \mathrm{PO}_{4}, 300 \mathrm{mM} \mathrm{NaCl}, 10 \mathrm{mM}$ imidazole, $\mathrm{pH}$ 8.0). Ultrasonication was carried out in an ice bath with 2-5 sec of $100 \mathrm{~W}$ ultrasound 60-80 times. The supernatant was mixed with half the volume of Ni-NTA Agarose beads (Qiagen) and agitated for $1 \mathrm{~h}$. After being washed by the wash buffer (binding buffer supplemented with $20 \mathrm{mM}$ imidazole) and eluted by the elution buffer (binding buffer supplemented with $250 \mathrm{mM}$ imidazole), the purified proteins were ultrafiltrated to change the solvent from the elution buffer to the binding buffer containing $3 \mathrm{M}$ urea, $\mathrm{pH} 9.5$ (to prevent core protein dimers from autoassembling into nucleocapsids). The proteins were again mixed with half the volume of Ni-NTA Agarose beads and agitated for $30 \mathrm{~min}$ at $4^{\circ} \mathrm{C}$. The conjugates (Ni-NTA agarose beads conjugated with core protein dimers or the negative control) were washed and suspended in the binding buffer with the addition of Complete Protease Inhibitor (Roche Diagnostics, Mannheim, Germany) and stored at $4^{\circ} \mathrm{C}$.

SELEX. An ssDNA library (5'-ACGCTCGGATGCCACTA

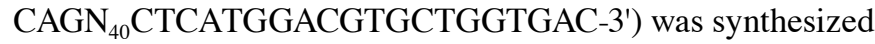
by Sangon Biotech (Shanghai, China). The ssDNA pool (200 pmol) (2.5 nmol ssDNA library was used for the initial round) was dissolved in $\mathrm{PBS}+\mathrm{Mg}$ (PBS supplemented with $1 \mathrm{mM} \mathrm{MgCl}$ ) and was denatured at $95^{\circ} \mathrm{C}$ for $8 \mathrm{~min}$ and quickly cooled on ice. Negative control conjugates (40 pmol) were washed twice by PBS $+\mathrm{Mg}$ and incubated with the ssDNA pool in a total volume of $1,000 \mu \mathrm{l}$ of PBS+Mg+tRNA (PBS+Mg supplemented with $0.1 \mathrm{mg} / \mathrm{ml}$ yeast tRNA) for $30 \mathrm{~min}$ at $37^{\circ} \mathrm{C}$, in an orbital shaker. The percolate containing unbound ssDNA sequences was then obtained through ultrafiltration, and was incubated with positive conjugates (consisting of core proteins and also washed with PBS+Mg twice), in an orbital shaker for $30 \mathrm{~min}$ at $37^{\circ} \mathrm{C}$. The mixture was ultrafiltrated and the remaining conjugates were washed three times by $\mathrm{PBS}+\mathrm{Mg}$ to remove unbound ssDNA sequences. The bound sequences were eluted by $10 \%$ trypsin $\left(10 \mathrm{~min}\right.$ at $\left.37^{\circ} \mathrm{C}\right)$ followed by heating at $95^{\circ} \mathrm{C}$ for $10 \mathrm{~min}$ and centrifugation at 5,000 rpm for 5 min. The sequences were amplified by PCR using the forward primer (5'-ACGCTCGGATGCCACTA CAG-3') and biotin-labeled reverse primer (5'-GTCACCAG CACGTCCATGAG-3'). The selected sense DNA strands were separated from the biotinylated antisense strands by alkaline denaturation $(0.2 \mathrm{M} \mathrm{NaOH})$ and affinity purification with streptavidin-coated Sepharose beads (GE Healthcare, Uppsala, Sweden). The entire selection procedure was repeated for several rounds according to the extent of enrichment. The enriched pool was amplified by PCR using unlabeled primers and the PCR products were cloned into Escherichia coli DH5a using pMD19 T-vector (Takara Bio Inc., Shiga, Japan) and the positive clones were sequenced and aligned by MACAW software (NIH, Bethesda, MD, USA).

Monitoring the enrichment of aptamer pools. The aptamer pool of each SELEX round was incubated with positive conjugates, ultrafiltrated, washed and eluted as described above. Quantitative PCR (qPCR) reactions (10 $\mu$ l reaction volume) were carried out using SYBR Premix Ex Taq ${ }^{\mathrm{TM}}$ (Takara Bio Inc.) according to the manufacturer's instructions in an Applied Biosystems 7500 sequence detection system (Applied Biosystems, Foster City, CA, USA). The proportion of bound sequences, which indicated the enrichment of the aptamer pool, was calculated as: $2^{\text {(Ct of input pool-Ct of elusion) }} \mathrm{x} 100 \%$.

Dot blot. Purified HBc $(2 \mu \mathrm{l} ; 10 \mu \mathrm{M})$ was spotted onto a polyvinylidene difluoride (PVDF) membrane (Bio-Rad Laboratories, Hercules, CA, USA) pretreated with methyl alcohol. After drying, the membrane was incubated with 5\% $\mathrm{BSA}$ in PBS+Mg+tRNA ( $1 \mathrm{~h}$, room temperature) to block non-specific sites. Subsequently, it was incubated with $200 \mu \mathrm{l}$ candidate aptamer $(0.1 \mu \mathrm{M})$ in $\mathrm{PBS}+\mathrm{Mg}+\mathrm{tRNA}\left(1 \mathrm{~h}, 37^{\circ} \mathrm{C}\right)$. After three washes with TBST, it was incubated with $200 \mu 1$ streptavidin-horseradish peroxidase conjugate (Rpn1231; Amersham Biosciences, Piscataway, NJ, USA) at a dilution of 1:1,000 in TBST $\left(45 \mathrm{~min}, 37^{\circ} \mathrm{C}\right)$. After another three washes, it was detected by SuperSignal West Pico Chemiluminescent Substrate (Thermo Fisher Scientific, Rockford, IL, USA) according to the manufacturer's instructions.

Cell culture and transfection. HBV DNA integrated cell line HepG2.2.15, which is derived from the HepG2 human hepatoma cell line and is characterized by stable HBV expression and replication, was maintained in Dulbecco's modified Eagle's medium (DMEM) containing 10\% fetal bovine serum (FBS) at $37^{\circ} \mathrm{C}$ in a humidified atmosphere with $5 \% \mathrm{CO}_{2}$.

For the transfection experiments, HepG2.2.15 cells were seeded in 6-well plates at a density of $4 \times 10^{5}$ in $2 \mathrm{ml}$ medium/well. After $24 \mathrm{~h}$ of incubation, transfection was accomplished with Hifectin III transfection reagent (Applygen Technologies, Beijing, China) according to the manufacturer's instructions. In brief, $8 \mu \mathrm{g}$ aptamer mixed with $8 \mu \mathrm{l}$ transfection reagent was applied to each well. Transfection reagent alone was applied as an experimental control. The cells were grown for a further 24,48 and $72 \mathrm{~h}$ prior to harvest.

Isolation and quantification of $H B V D N A, H B s A g$ and HBeAg. The intracellular HBV DNA was isolated by TRI reagent (Sigma-Aldrich Inc., St. Louis, MO, USA) according to the manufacturer's instructions. The extracellular HBV DNA in culture medium was extracted by the AxyPrep Blood Genomic DNA Miniprep kit (Axygen Biosciences, Union City, CA, USA). Following the extraction, the absorbance at 260/280 nm was measured using a NanoDrop ND-1000 spectrophotometer 
(Bio-Lab Australia Pty Ltd., Mulgrave, VIC, Australia) and the concentrations were calculated.

HBV DNA was quantified by qPCR as described above, with the primers described by Jun-Bin et al (19). The amplification program was: pre-denaturation at $95^{\circ} \mathrm{C}$ for $30 \mathrm{sec}$, 40 cycles of $95^{\circ} \mathrm{C}$ for $5 \mathrm{sec}$ and $64^{\circ} \mathrm{C}$ for $34 \mathrm{sec}$.

$\mathrm{HBsAg}$ and $\mathrm{HBeAg}$ in culture medium were determined by using the relative quantitative ELISA kits (Shanghai Kehua Bio-engineering Co., Ltd., Shanghai, China) (20). In brief, the culture media were diluted to a ratio of 1:6 with PBS and added to plates coated with antibody against $\mathrm{HBsAg}$ or $\mathrm{HBeAg}$, respectively. After $30 \mathrm{~min}$ of incubation at $37^{\circ} \mathrm{C}$, the plates were washed and incubated with substrate solution A or $\mathrm{B}$, respectively $\left(15 \mathrm{~min}\right.$ at $37^{\circ} \mathrm{C}$, protected from light). The reaction was stopped by the termination solution and the optical density (OD) value at $450 \mathrm{~nm}$ was measured.

Assay for HBV nucleocapsids. To separate the nucleocapsids based on Calvert and Summers' protocol (21), cell lysates, which were achieved by cell lysis buffer for western blot analysis and IP (Beyotime Institute of Biotechnology, Haimen, China), were loaded onto native $0.8 \%$ agarose-Tris-acetateEDTA (TAE) gel electrophoresis. The bands were blotted onto PVDF membrane overnight at $4^{\circ} \mathrm{C}$ by capillary transfer in 10X SSC buffer (1.5M NaCl, $150 \mathrm{mM}$ sodium citrate, $\mathrm{pH} 7.0$ ). After drying, similar to the general western blot analysis, the membrane was rinsed in TBST containing 5\% skim milk to block non-specific sites, followed by three washes in TBST, with agitation for $10 \mathrm{~min}$ each. The membrane was then incubated with the antibody against HBc (Santa Cruz Biotechnology, Santa Cruz, Inc., CA, USA) at a dilution of 1:500 in solution 1 of the SignalBoost Immunoreaction Enhancer kit (Merck KGaA, Darmstadt, Germany) for 2 h. It was then washed as described above and incubated with a horseradish peroxidase (HRP) conjugated secondary antibody (Santa Cruz Biotechnology, Inc.) at a dilution of 1:1,000 in solution 2 of the SignalBoost Immunoreaction Enhancer kit for $2 \mathrm{~h}$. After another three washes, it was detected by Immobilon Western Chemiluminescent HRP Substrate (Millipore Corp., Billerica, MA, USA) according to the manufacturer's instructions. The $\beta$-actin bands in cell lysates, obtained by general western blot analysis, were used as an internal reference.

\section{Results}

An aptamer pool binding to $H B c$ was screened from an ssDNA library. To screen for aptamers against $\mathrm{HBc}$, we performed nine rounds of SELEX with His-tagged $\mathrm{HBc}$ as target and His-tagged plain vector as a counter-selector. Enrichment was observed following qPCR of ssDNA pools of all rounds (Fig. 1A). It was shown that the proportion of bound sequences increased with the proceeding of the SELEX, until round seven. Subsequently, the pools ceased to enrich and were even slightly attenuated, possibly due to amplification bias (22). Thus, the pool of round seven was expected to contain the ideal aptamer(s) and was subsequently amplified and cloned.

A total of 90 positive clones were sequenced. By analysis in MACAW, most of the clones were subdivided into seven groups, each of which contained a consensus five-letter sequence (Fig. 1B). In particular, clone No.28 had a replicate
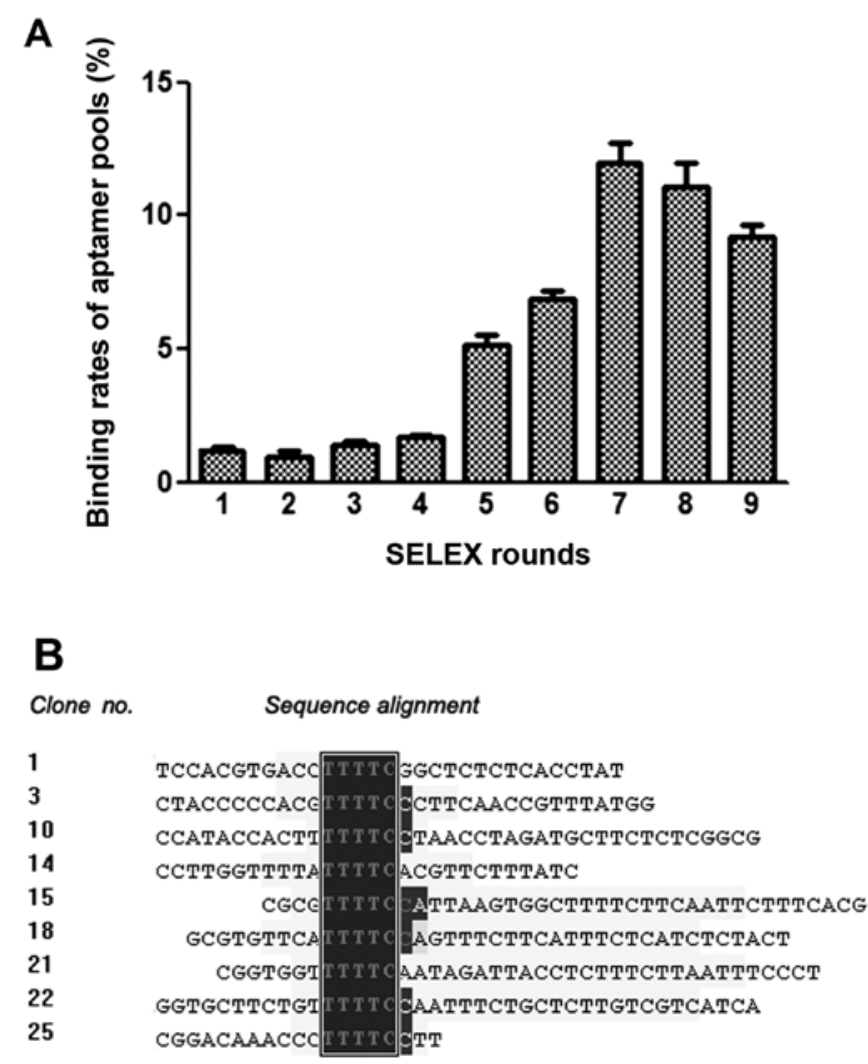

Figure 1. Enrichment of aptamer pools in SELEX. (A) The enrichment, which was represented by the proportion of sequences bound to positive conjugates, is shown by qPCR. (B) A representative view of the consensus of clones from the enriched pool, based on which aptamer candidates were selected.

in sequence (No.33), as was the case in clone No.29 (No.66). Thus, one clone each from the five largest groups was selected for subsequent studies, i.e., clone No.1, 12, 16, 28 and 29 from group 1, 5, 4, 2 and 3, respectively, among which the replicated clones (No.28 and No.29) were specifically selected (Table I).

Candidate aptamer Apt.No.28 has high affinity and specificity to $H B c$. To verify the binding affinity of the candidate aptamers, a dot blot was carried out with purified HBc dotted on PVDF membrane and candidate aptamers in the liquid phase. It was shown that as compared to the unselected library, candidate aptamers had divergent affinity to the target, among which Apt.No.28 and No.29 had the highest (Fig. 2A and B). Thus, these two candidates were subjected to the subsequent studies.

We also tested Apt.No.28 in the detection of HBV nucleocapsids from cell lysates of HepG2.2.15 and compared it to the HBc antibody. Both Apt.No.28 and the antibody were feasible in the detection of the nucleocapsids (Fig. 2C). However, the antibody also strongly stained the protein markers while the aptamer did not stain these markers, suggesting that the aptamer was more specific to $\mathrm{HBc}$ and the nucleocapsids.

Apt.No.28 attenuates extracellular HBV DNA but not the secretion of $H B V$ capsids. In order to investigate whether the candidate aptamers targeting $\mathrm{HBc}$ were able to interfere with the replication of HBV, ELISA assay and qPCR were used to quantify the HBV of aptamer-transfected HepG2.2.15. 
Table I. The selected aptamer candidates.

\section{Clone}

no.

A

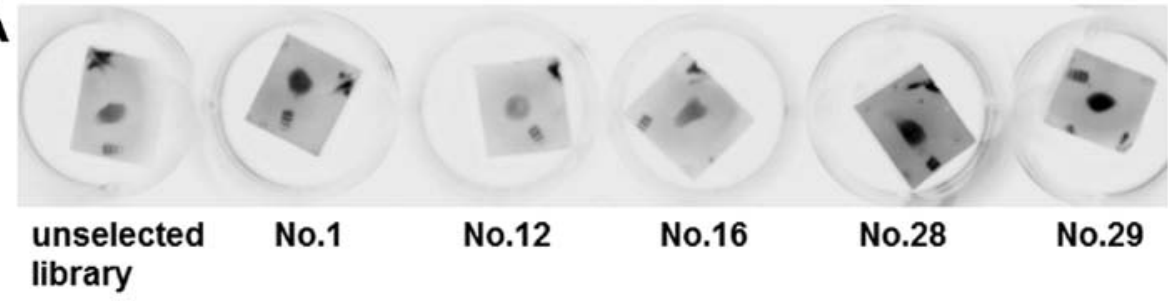

B

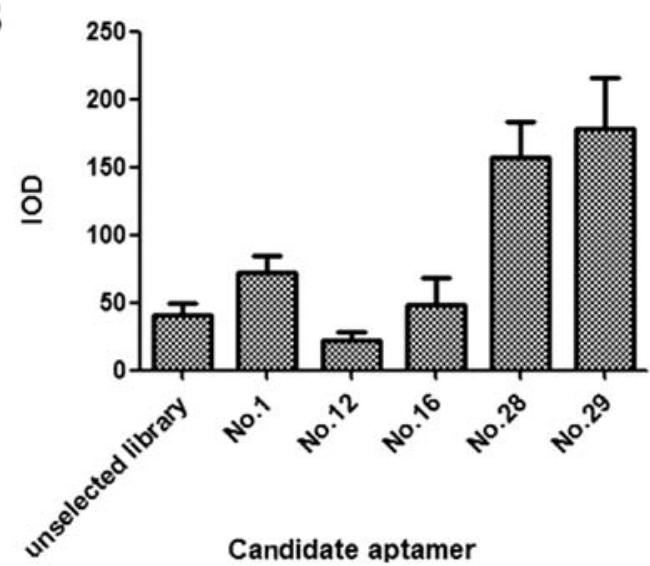

C

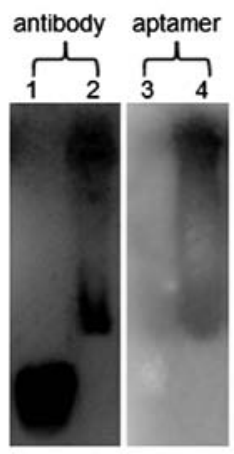

Figure 2. Affinity and specificity of the candidate aptamers to HBc. (A) The affinity of candidate aptamers to core protein evaluated by dot blot. (B) The digitized integrated optical density (IOD) of the dot blots. (C) The blots of protein markers (lanes 1 and 3 ) and the nucleocapsids in HepG2.2.15 cell lysates (lanes 2 and 4), which were obtained by agarose gel electrophoresis, capillary transfer, and staining by the antibody against HBc or the aptamer Apt.No.28.

In the ELISA assay, HepG2.215 did not lose the ability of secreting HBV capsids (no decrease in HBsAg or HBeAg) following transfection with Apt.No.28 or No.29 (Fig. 3A and B). However, the alteration was observed on extracellular HBV DNA by qPCR analysis. As shown in Fig. 3C, $24 \mathrm{~h}$ after the transfection, the level of extracellular HBV DNA in the groups transfected with Apt.No.28 and No.29 showed no significant difference to that transfected with the unselected library. At $48 \mathrm{~h}$, the amount of extracellular HBV DNA in the group of Apt.No.28 was significantly less, while that in the group of Apt.No.29 showed little difference. The trend at $72 \mathrm{~h}$ was similar to that at $48 \mathrm{~h}$. Apt.No.28 and No.29 did not reduce the intracellular level of HBV DNA (Fig. 3D). These findings indicated that Apt.No.28 was able to inhibit the replication of HBV by suppressing the synthesis of HBV DNA.

Apt.No.28 inhibits the assembly of nucleocapsids. To study the mechanism involved in the inhibition of HBV replication by Apt.No.28, the total intracellular protein was extracted from HepG2.2.15 cells transfected with Apt.No.28 for $72 \mathrm{~h}$. Using agarose gel electrophoresis, capillary transfer and blotting, it was shown that the nucleocapsids formed by $\mathrm{HBc}$ were significantly less in the group treated with Apt.No.28 than those in the group treated with the library (Fig. 4A and B). These findings indicated that Apt.No.28 inhibited HBV replication by interfering with the assembly of nucleocapsid, which was essential to the synthesis of HBV DNA.

\section{Discussion}

Although HBV was identified in 1885 and its basic constructional elements have already been isolated and identified, drugs with high specificity to HBV are under development, due to the easy occurrence of side-effects and drug resistance (23). Thus, new technologies are required to solve these problems and overcome limitations to HBV. Aptamer is a newly developed adaptive molecule that shows high sensitivity and specificity, while exhibiting no toxicity or immunogenicity $(8,24,25)$. It 

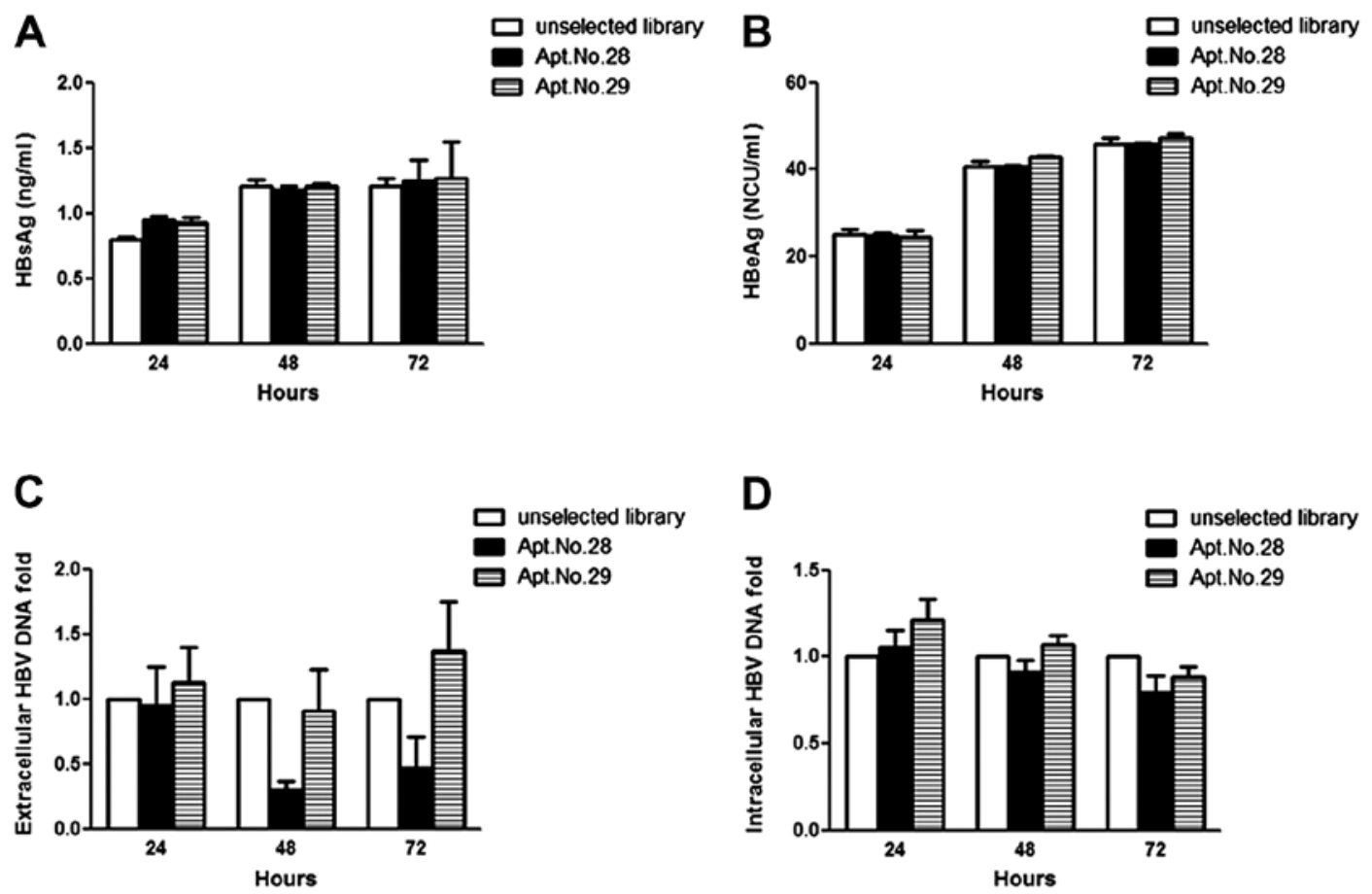

Figure 3. Effect of the candidate aptamers on HBV level. (A) HBsAg, (B) HBeAg, (C) the extracellular HBV DNA and (D) the intracellular HBV DNA of HepG2.2.15 cells 24, 48 and $72 \mathrm{~h}$ following transfection with Apt.No.28 or Apt.No.29.
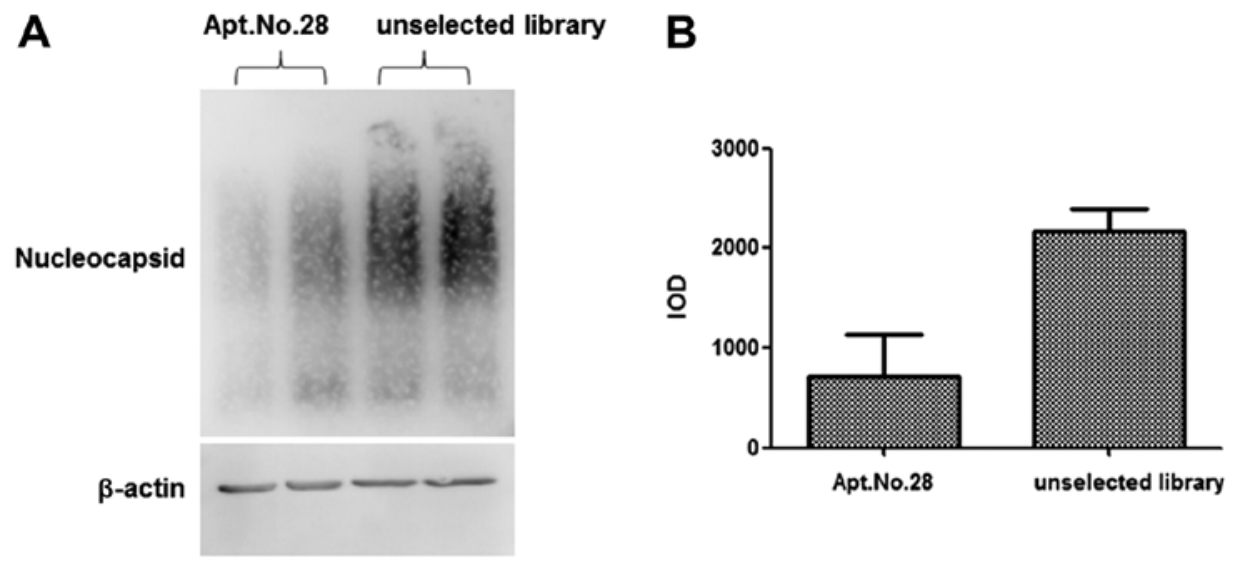

Figure 4. The inhibitory effect of Apt.No.28 on the assembly of HBV nucleocapsids. (A) The blots of HBV nucleocapsids from HepG2.2.15 cell lysates $72 \mathrm{~h}$ following transfection with Apt.No.28 or the unselected library. (B) The digitized integrated optical density of the blots of the nucleocapsids is shown.

becomes more and more prevalent in basic research as well as clinical practice. Thus, it is believed that its use in antiviral research may reveal the propagation, block the infection and inactivate the viability of viruses. The aptamers for HCV and HIV have been developed thus far and are altering antiviral investigations as well as clinical diagnosis and treatments $(10,13)$. In particular, the in vivo therapeutic use of a HIV aptamer has been reported in Science Translational Medicine (14). However, the application of aptamers in antiHBV research is in the early stages, most probably due to the complexity of HBV.

$\mathrm{HBc}$ is the major component of the nucleocapsid packaging HBV genome. It is involved in the processes of viral replication and regulation, such as RNA packaging, DNA synthesis, recognition of virus envelope, maturation and budding of virus.
Of note, $\mathrm{HBc}$ is capable of assembling the nucleocapsid in a native shape (with 180 or 240 core protein units) automatically, in circumstances lacking all other viral components $(26,27)$. Therefore, the control of $\mathrm{HBc}$ and the nucleocapsids may be essential to anti-HBV strategies. Thus, we screened DNA aptamers targeting $\mathrm{HBc}$ in this study.

There are currently few reports regarding the technology of the expression and purification of $\mathrm{HBc}$. The most common approach is to express $\mathrm{HBc}$ as inclusion bodies, which is subsequently purified by a process of wash, denaturation and renaturation (28-30). However, the manipulation of inclusion bodies can easily cause the loss of proteins, while renaturation remains a challenge (31). Thus, when the expression level is relatively low, proteins dissolved in the bacterial cytoplasm are easier to extract with large quantity and good solubility in the 
supernatant following ultrasonication (32). Furthermore, since $\mathrm{HBc}$ was automatically assembled into the nucleocapsid form while the dimer form was required for aptamer selection, the extracted core proteins were further depolymerized to dimers by the treatment of urea and alkali and bound to the Ni-NTA agarose beads for purification in the present study.

The fact that $\mathrm{HBc}$ is automatically assembled to polymers in the neutral $\mathrm{pH}$ range makes the protein purification and aptamer selection complicated and limits the methods available for aptamer identification. In this study, dot blot was used to verify the affinity of aptamers. In order to maintain its dimeric form, $\mathrm{HBc}$ was also treated with urea and alkali, dotted onto a PVDF membrane, dried and adjusted to a neutral $\mathrm{pH}$ range. In contrast to the aptamer studies targeting $\mathrm{S}$ protein or the polymerase of $\mathrm{HBV}$, the automatic polymerization of $\mathrm{HBc}$ may account for the limitation in the study of its aptamers. Findings of this study may facilitate additional investigations of HBc.

The sequence replication of clones was a typical characteristic of aptamer enrichment. Apt.No.28 and No.29, which had sequence replicates, were shown to have high affinity to $\mathrm{HBc}$, although the possibility could not be excluded that clones with higher affinity and even functional effects were not selected for the present study.

To value the function of candidate aptamers in live cells, we transferred them into HepG2.2.15 cells by transfection reagent to test their inhibitory effect on HBV replication. As the main indices of HBV level, it was identified that HBV capsid (shown by $\mathrm{HBsAg}$ and $\mathrm{HBeAg}$ ) was not inhibited by the aptamer Apt. No.28, whereas extracellular HBV DNA was inhibited by the aptamer Apt.No.28. This finding suggests that the inhibitory effect of Apt.No.28 on HBV replication did not occur during the expression of $\mathrm{HBV}$ proteins, but occurred prior to synthesis of HBV DNA reversely transcribed by HBV RNA, which was after and depended on the assembly of the nucleocapsid. By agarose gel electrophoresis, capillary transfer and blotting, we found that the assembly of the nucleocapsid was inhibited by Apt.No.28. Therefore, it was confirmed that the aptamer inhibited the replication of HBV by binding to core protein dimers and inhibiting the assembly of nucleocapsid.

The inhibitory effect of Apt.No.28 was to some extent limited by cell transfection. The transfection reagent used in this study was Hifectin III, which was specific for the transfection of ssDNA. We had also tried a general transfection reagent Lipofectamine 2000 (Invitrogen), but yielded low transfection efficiency. To strengthen the effect of Apt.No.28, a targeted delivery system may be required. A conjugation with an aptamer against hepatocytes is an ideal strategy (e.g., the aptamer against hepatoma HA09) (22).

Previous studies have described peptide aptamers that could specifically bind to $\mathrm{HBc}(20,33,34)$. However, considering certain disadvantages of polypeptides and proteins such as instability and immunogenicity, the DNA aptamer we identified, which interfered with HBV replication at the stage of nucleocapsid assembly, was thought to have greater potential in the detection of $\mathrm{HBc}$, and in the treatment of HBV-related diseases.

Nevertheless, additional studies are required to identify the underlying structural basis and molecular mechanism of the recognition and polymerization inhibition of $\mathrm{HBc}$ by the aptamer. Studies should also be carried out to examine the potential effects of the aptamer on HBV, such as the anti-HBV effect of modified aptamers in vivo.

\section{Acknowledgements}

We would like to thank Dr Youhua Xie (from the Shanghai Medical School, Fudan University) for kindly providing the plasmid pBS_HBV3.6II. We also thank Drs Li Xu and Xiaohong Fang (from the Institute of Chemistry, Academy of Sciences, China) for their assistance in designing the SELEX protocol. The present study was supported by grants from the National Natural Science Foundation of China (nos. 81125001 and 91129702) and the Ministry of Science and Technology of China (no. 2010CB732405).

\section{References}

1. Ma X, Lin C and Zhen W: Cancer care in China: a general review. Biomed Imaging Interv J 4: e39, 2008.

2. Vigano $M$ and Lampertico P: Antiviral drugs for HBV liver disease. Expert Opin Biol Ther 11: 285-300, 2011.

3. Yan H,Zhong G, Xu G, et al: Sodium taurocholate cotransporting polypeptide is a functional receptor for human hepatitis B and D virus. Elife 1: e00049, 2012.

4. Roseman AM, Berriman JA, Wynne SA, Butler PJ and Crowther RA: A structural model for maturation of the hepatitis B virus core. Proc Natl Acad Sci USA 102: 15821-15826, 2005.

5. Deres K, Schroder CH, Paessens A, et al: Inhibition of hepatitis $\mathrm{B}$ virus replication by drug-induced depletion of nucleocapsids. Science 299: 893-896, 2003.

6. Kulbachinskiy AV: Methods for selection of aptamers to protein targets. Biochemistry (Moscow) 72: 1505-1518, 2007.

7. Sefah K, Shangguan D, Xiong X, O'Donoghue MB and Tan W: Development of DNA aptamers using Cell-SELEX. Nat Protoc 5: $1169-1185,2010$.

8. Chakravarthy U, Adamis AP, Cunningham ETJ, et al: Year 2 efficacy results of 2 randomized controlled clinical trials of pegaptanib for neovascular age-related macular degeneration. Ophthalmology 113: 1508.e1501-1508.e1525, 2006.

9. Ng EW, Shima DT, Calias P, Cunningham ET Jr, Guyer DR and Adamis AP: Pegaptanib, a targeted anti-VEGF aptamer for ocular vascular disease. Nat Rev Drug Discov 5: 123-132, 2006.

10. Ramalingam D, Duclair S, Datta SA, Ellington A, Rein A and Prasad VR: RNA aptamers directed to human immunodeficiency virus type $1 \mathrm{Gag}$ polyprotein bind to the matrix and nucleocapsid domains and inhibit virus production. J Virol 85: 305-314, 2011.

11. Kikuchi K, Umehara T, Fukuda K, Kuno A, Hasegawa T and Nishikawa S: A hepatitis C virus (HCV) internal ribosome entry site (IRES) domain III-IV-targeted aptamer inhibits translation by binding to an apical loop of domain IIId. Nucleic Acids Res 33: 683-692, 2005 .

12. Kikuchi K, Umehara T, Nishikawa F, Fukuda K, Hasegawa T and Nishikawa S: Increased inhibitory ability of conjugated RNA aptamers against the HCV IRES. Biochem Biophys Res Commun 386: 118-123, 2009.

13. Chen F, Hu Y,Li D, Chen H and Zhang XL: CS-SELEX generates high-affinity ssDNA aptamers as molecular probes for hepatitis C virus envelope glycoprotein E2. PLoS One 4: e8142, 2009.

14. Neff CP, Zhou J, Remling L, et al: An aptamer-siRNA chimera suppresses HIV-1 viral loads and protects from helper $\mathrm{CD}^{+}$ $\mathrm{T}$ cell decline in humanized mice. Sci Transl Med 3: 66ra66, 2011.

15. Zhou J, Li H, Li S, Zaia J and Rossi JJ: Novel dual inhibitory function aptamer-siRNA delivery system for HIV-1 therapy. Mol Ther 16: 1481-1489, 2008

16. Liu J, Yang Y, Hu B, et al: Development of HBsAg-binding aptamers that bind HepG2.2.15 cells via HBV surface antigen. Virol Sin 25: 27-35, 2010.

17. Feng H, Beck J, Nassal M and Hu KH: A SELEX-screened aptamer of human hepatitis B virus RNA encapsidation signal suppresses viral replication. PLoS One 6: e27862, 2011.

18. Ray P and White RR: Aptamers for targeted drug delivery. Pharmaceuticals 3: 1761-1778, 2010. 
19. Jun-Bin S, Zhi C, Wei-Qin N and Jun F: A quantitative method to detect HBV cccDNA by chimeric primer and real-time polymerase chain reaction. J Virol Methods 112: 45-52, 2003.

20. Zhang W, Ke W, Wu SS, et al: An adenovirus-delivered peptide aptamer C1-1 targeting the core protein of hepatitis B virus inhibits viral DNA replication and production in vitro and in vivo. Peptides 30: 1816-1821, 2009.

21. Calvert J and Summers J: Two regions of an avian hepadnavirus RNA pregenome are required in cis for encapsidation. J Virol 68 : 2084-2090, 1994.

22. Lu B, Wang J, Zhang J, et al: Screening and verification of ssDNA aptamers targeting human hepatocellular carcinoma. Acta Biochim Biophys Sin (Shanghai) 46: 128-135, 2014

23. Devi U and Locarnini S: Hepatitis B antivirals and resistance. Curr Opin Virol 3: 495-500, 2013.

24. Ferapontova EE and Gothelf KV: Recent advances in electrochemical aptamer-based sensors. Curr Org Chem 15: 498-505, 2011.

25. Chu TC, Marks JW III, Lavery LA, et al: Aptamer: toxin conjugates that specifically target prostate tumor cells. Cancer Res 66: 5989-5992, 2006.

26. Wang JC, Dhason MS and Zlotnick A: Structural organization of pregenomic RNA and the carboxy-terminal domain of the capsid protein of hepatitis B virus. PLoS Pathog 8: e1002919, 2012.

27. Vanlandschoot P, Van Houtte F, Serruys B and Leroux-Roels G: The arginine-rich carboxy-terminal domain of the hepatitis $B$ virus core protein mediates attachment of nucleocapsids to cellsurface-expressed heparan sulfate. J Gen Virol 86: 75-84, 2005.
28. Jammeh S, Tavner F, Watson R, Thomas HC and Karayiannis P: Effect of basal core promoter and pre-core mutations on hepatitis B virus replication. J Gen Virol 89: 901-909, 2008.

29. Guo H, Jiang D, Zhou T, Cuconati A, Block TM and Guo JT: Characterization of the intracellular deproteinized relaxed circular DNA of hepatitis B virus: an intermediate of covalently closed circular DNA formation. J Virol 81: 12472-12484, 2007.

30. Schmitz A, Schwarz A, Foss M, et al: Nucleoporin 153 arrests the nuclear import of hepatitis B virus capsids in the nuclear basket. PLoS Pathog 6: e1000741, 2010.

31. Masri HP and Cornelissen CN: Specific ligand binding attributable to individual epitopes of gonococcal transferrin binding protein A. Infect Immun 70: 732-740, 2002.

32. Yamada $N$ and Tanoue E: Detection and partial characterization of dissolved glycoproteins in oceanic waters. Limnol Oceanogr 48: 1037-1048, 2003.

33. Tomai E, Butz K, Lohrey C, von Weizsacker F, Zentgraf H and Hoppe-Seyler F: Peptide aptamer-mediated inhibition of target proteins by sequestration into aggresomes. J Biol Chem 281: 21345-21352, 2006.

34. Butz K, Denk C, Fitscher B, et al: Peptide aptamers targeting the hepatitis B virus core protein: a new class of molecules with antiviral activity. Oncogene 20: 6579-6586, 2001. 